\title{
Saudi Woman's Cycling Trend and Sportswear Preferences
}

\author{
Afnan Salem Al-Tayyar, Maha Abdullah Al Dabbagh \\ King Abdulaziz University, Jeddah, Makkah, KSA \\ Email: afnan-salem@hotmail.com, Maldabag@kau.edu.sa
}

How to cite this paper: Al-Tayyar, A. S., \& Al Dabbagh, M. A. (2021). Saudi Woman's Cycling Trend and Sportswear Preferences. Open Journal of Social Sciences, 9, 293-304. https://doi.org/10.4236/jss.2021.92020

Received: January 11, 2021

Accepted: February 20, 2021

Published: February 23, 2021

Copyright $\odot 2021$ by author(s) and Scientific Research Publishing Inc. This work is licensed under the Creative Commons Attribution International License (CC BY 4.0).

http://creativecommons.org/licenses/by/4.0/ (c) (i) Open Access

\begin{abstract}
In Saudi Arabi, women's practice of cycling is governed by some regulations and controls that take into account traditional, religious, and social considerations. Such regulations and controls are meant to protect women against potential street accidents or abuses. This research examines Saudi woman's preferences for cycling clothes, and the current situation of women's practice of cycling in Saudi Arabia with the aim to produce some recommendations that could enable sportswear designers to produce women's cycling clothes that take into account and respect social and religious values. A questionnaire was designed to examine cycling trend of Saudi Women, and solicit the opinions of 52 women on the availability of modest cycling sportwear as well as their general preferences for cycling clothes. Using a quantitative method, the research's findings have shown tendency among a majority of surveyed women to wear specialized and modest cycling clothes in public places, thus signifying the need to design specialized and modest sportswear for women that conforms to traditional values and Islam teachings.
\end{abstract}

\section{Keywords}

Women's Cycling, Sportswear Designers, Cycling Sportswear, Traditional and Cultural Values

\section{Introduction}

Sports has received great attention in the Saudi Arabia's Vision 2030, which was launched on April 25, 2016, under the patronage of the Custodian of the Two Holy Mosques, King Salman bin Abdulaziz. The Vision has emphasized that the Kingdom, with a close follow-up by Crown Prince Mohammed bin Salman, shall encourage all kinds of sports in order for the Saudi community to excel in sport and be among the leaders in selected sports regionally and globally. The Saudi 
women's community has a remarkable tendency towards achieving the goals of the Vision which aims to encourage widespread and regular participation in sports and athletic activities. The Vision 2030 also aims to ensure a healthy and balanced lifestyle as being an essential mainstay of high quality of life, including through the promotion of sporting activities in the community, and achieving excellence in several sports at the regional and global level.

Cycling is considered one of the oldest and most important physical activities among other types of sports. Accordingly, women's practicing of cycling has continued to present time. Today, cycling is the most important widespread sport physical activity on earth, and one of the methods for sport and therapeutic rehabilitation of the human body at present. Due to the availability and low prices of bikes, cycling has become one of the most common sports that are practiced by all age groups all over the world. It is also one of the most enjoyable and entertaining sports that help improve the efficiency of the heart and lungs, increase stamina, and improve the agility of the lower part of the body (Jazouli, 2019).

However, there has been too much controversy regarding women's cycling clothes and practice since the nineteenth century to the present day. Women's cycling has necessitated a change in women's fashion (Kiersnowska, 2019). In this paper, the researcher particularly examines Saudi woman's preferences for cycling clothes, and investigates the current situation of women's practice of cycling in the Kingdom, with the aim to produce some recommendations that would enable sportswear designers to produce women's cycling clothes that conform to and respect social and religious values.

\section{Research Problem}

The research problem lies in the lack of women's modest cycling clothes that meet the requirements of Saudi women and conforms to Arab societal traditions and ethics.

\section{Research Questions}

- What do Saudi women prefer to wear for cycling?

- Is there a need to design a specialized sportswear for women?

- Are there some specialized sportswear stores in Saudi Arabia that sell women cycling clothes which meet the requirements of Arab societal traditions and ethics?

\section{Research Significance}

The research highlights the need to introduce special cycling sportswear for Saudi women, especially in light of a growing interest in practicing this type of sport.

\section{Research Methodology}

Researches can be carried out using different approaches, depending on the 
nature and aim the research. In making this paper, the researcher has conducted a survey research; a quantitative method in which he collected information from a pool of respondents by asking multiple survey questions. This research type includes the recruitment of individuals, collection, and analysis of data. The researcher has also reviewed literature on cycling sport from various resources as well as from some Saudi local newspapers publishing articles on the participation of Saudi women in cycling sport.

\section{Literature Review}

\subsection{Evolution of Cycling}

Cycling, also called cycling or biking, is the use of bicycles for transport, recreation, exercise or sport, (Oxford English Dictionary, 1989). People engaged in cycling are referred to as "cyclists", "bicyclists", or "bikers". The bicycle, bike or cycle is a human-powered vehicle that is driven by foot pedals. It has a basic frame with two wheels attached to it, one after the other.

In 1868, Britain witnessed the production of the first bicycles and it quickly developed into a profitable industry fuelled by a rapidly growing market. Continuous technological advances, particularly the introduction of Dunlop's pneumatic tyres in 1888, and a growing market in cheaper second-hand bicycles (Flanders, 2007: p. 454; Mackintosh \& Norcliffe, 2007: p. 157; Reid, 2015: p. 247) helped transform the bicycle from a costly fashionable sports item to a more universal utilitarian means of transport and recreation-one of the technological marvels of the Victorian era (Rubinstein, 1977: p. 48).

\subsection{Cycling and Feminism}

Cycling as recreation became organized shortly after racing did. Since its early days, cycling brought the sexes together in an unchaperoned way, particularly after the 1880s when cycling became more accessible owing to the invention of the Rover Safety bicycle. Public cries of alarm at the prospect of moral chaos arose from this and from the evolution of women's cycling attire, which grew progressively less enveloping and restrictive (Encyclopædia Britannica, 2020).

The practice of cycling had a significant impact on the lives of women in many topics (Willard, 1895; Stanton, 1902). The greatest impact the bicycle had on the role of women occurred in the 1890s during the bicycle craze that swept American and European society (Rubinstein, 1977). During this time, the primary achievement the bicycle gained for the women's movement is that it gave women a greater amount of social mobility (Harmond, 1971; Hallenbeck, 2010). The feminist Annie Londonderry accomplished her around-the-globe bicycle trip as the first woman in this time, (Blickenstaff, 2016; Total Women's Cycling, 2020). Due to the expense and various payment plans offered by American bicycle companies, the bicycle was affordable to everyone in society, (Harmond, 1971). However, the bicycle impacted upper and middle-class white women the most, (Harmond, 1971). This new change has transformed women's role in so- 
ciety from remaining in the domestic sphere as caregivers, housewives, and mothers to one of greater public appearance and involvement in the community (Harmond, 1971; Christie-Robin et al., 2012; Hallenbeck, 2010).

\subsection{Pre-Bicycle Craze Cycling}

Before the 1890s, using of bicycles as a mean of transport was not very popular. It was very difficult and dangerous to drive the standard bicycle or the high wheeler. Men, at that time, used to drive the ordinary bicycles, while women were only allowed to use specific types of bicycles such as the two-seater sociable, the tandem, and the tricycle. Beginning in the late 1860s companionate riding became a popular social activity for men and women. However, up until the mid 1880s, women were basically dependent upon men in order to participate in cycling. The presence of a man in control of the sociable assumed that the man could keep the woman safe from the dangers of riding a bike alone, thereby assuming the authority of man. So, while companionate riding was revolutionary in the development in sociability between men and women, it kept women in an inferior position to men by assuming that the man had the power over the bicycle in that situation, (Harmond, 1971; Christie-Robin et al., 2012).

\subsection{Social Controversy over Women's Cycling Attire}

Between 1885 and 1895, inventors and engineers managed to increase the safety of bicycles and introduced what was then called safety bicycle, (Harmond, 1971). At that time, special types of safe bicycles were developed for women in a way that would accommodate women's clothes. However, women fashion at that time made cycling difficult to practice; as women at that time used to wear long skirts and tight-fitted bodices that were not suitable to practice cycling. Therefore, fashion designer at that time offered special women outfits that would accommodate the bicycle including divided skirts, skirts that shortened with drawstrings, skirts that converted to bloomers, skirt-securing devices that kept the fabric close to the ankle, and a bicycle corset consisting of a sturdy, straight under-bodice with extra back support and a looser fit, (Christie-Robin et al., 2012). However, these types of clothes were met with mixed approval. Elizabeth Cady Stanton in her notes on whether or not women should ride a bicycle stated, "To sum up, I would say, let women ride ... If some prefer the [bulk] skirts flying in the wind exhausted in the wheels let them run the risk of their folly; If others prefer bloomers let them enjoy their choice if others prefer knickerbockers, leave them in peace" (Stanton, 1902).

Many writers claimed at that time that wearing bicycle costumes made it easier for women to ride a bicycle, (Brown, 1895). Men were the main opponents of women wearing bicycle clothing and in particular, bloomers. They considered these suits and in particular bloomers as ugly or shameful. In particular, they saw these bicycle costumes as a physical representation of women stealing men's characteristics, thereby blurring the lines between femininity and masculinity 
and what is socially acceptable for each group. What this fear reveals is a realistic notion that women were taking on a greater role of independence of which had previously been characterized as masculine, (Harmond, 1971; Christie-Robin et al., 2012).

\subsection{Women Cycling in Arab Culture}

The above lines have presented an overview of the evolution and status of women's cycling in the Western culture. However, the situation in the Arab and Muslim world is different, as there are many traditional and religious teachings that govern women's social practices such as cycling.

In terms of religion, Muslim women are instructed to wear a hijab; a veil worn by most Muslim women in the presence of any male outside of their immediate family, which usually covers the head and chest, and sometimes the face. The term hijab can refer to any head, face, or body covering worn by Muslim women that conforms to Islamic standards of modesty. The Qur'an instructs Muslim women to dress modestly, (Martin et al., 2003) and these guidelines can also be found in texts of hadith and fiqh developed after the revelation of the Qur'an and are derived from Qur'an verses (ayahs) referencing hijab, (Encyclopedia of Islam and the Muslim World, 2003). In countries where traditional Islamic beliefs prevail, women must wear the hijab in public and when they participate in physical activities (Pfister, 2010). However, "modest" dress does not necessarily restrict the activity range. Many Muslim women, however, prefer to participate in physical activities in women-only facilities not least because this allows them to wear sports clothes and be untroubled by the men.

In some Muslim countries, women generally wear traditional abaya. The abaya, sometimes also called an aba, is a simple, loose over-garment, essentially a robe-like dress. Traditional abaya is mostly black and may be either a large square of fabric draped from the shoulders or head or a long kaftan. The abaya covers the whole body except the head, feet, and hands. In this paper, the researcher proposes the invention of a special sportswear that enable woman to practice cycling while observing government regulations, social norms and religious teachings.

\subsection{Practice of Cycling in Saudi Arabia}

In Saudi Arabia, cycling is becoming increasingly popular among women, although it is practiced in a controlled way that protects women from potential street abuse or accidents. The Kingdom has encouraged sports of all kinds in order for the community to excel in sports at the local and international levels. The Saudi women's community has a tendency towards achieving the goals of the vision which aims to raise the percentage of sports practitioners in the society. The Vision 2030 also aims to ensure a balanced life for individuals, families and the broad society through several goals, including through the promotion of sporting activities in the community, and achieving excellence in several sports 
at the regional and global level.

Today, life for women in Saudi Arabia is changing quickly. They are now experiencing new liberties, such as riding a bicycle, although with special conservative conditions that confine practice of cycling to dedicated places, including parks and other open places, and stipulates that women be always accompanied by one of her male relatives (mahram: a woman's unmarriageable person) and away from the public disturbances.

In 2018, a research by the General Sports Authority (GSA) showed that there was a significant increase in the number of Saudis embracing sports and exercise and trying to get healthy. Cycling in particular is growing in Saudi Arabia, with various races and cycling groups popping up in major cities across the Kingdom. According to Saudi Gazette, official figures showing that $1.1 \%$ of the population cycle on a weekly basis, 32\% of those cyclers are women (Saudigazette, 2020). Most recently, A Saudi Arabia's first female cycling championship was held and saw ten cyclists from throughout the Kingdom took part in the time-challenge competition held under the supervision of the Saudi Cycling Federation (Arab News, 2020).

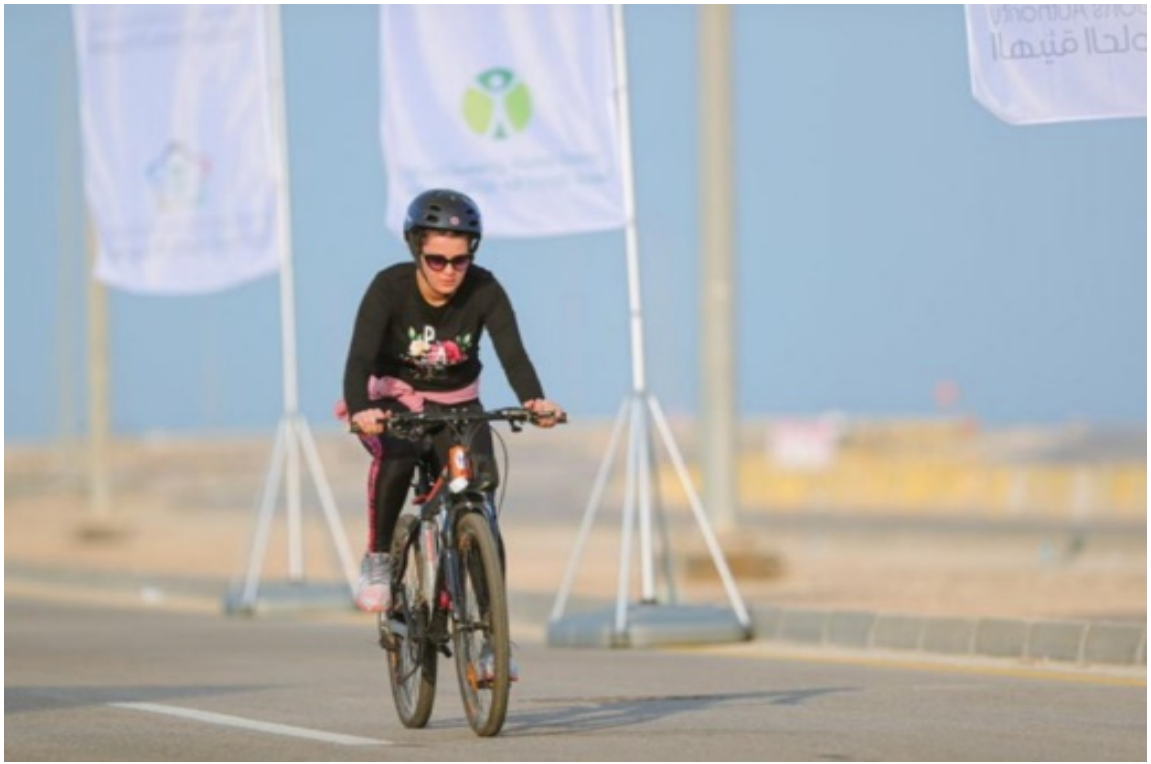

More than 1000 women participated in the Sport for All cycling race in Jeddah, Riyadh, Khobar Photo credit: http://www.almowaten.net/.

Women in Saudi Arabia are rapidly gaining more social liberties under a reform agenda spearheaded by Crown Prince Mohammed bin Salman bin Abdulaziz. The kingdom has seen an expansion in women's rights including a decision to allow women to attend mixed public sporting events and the right to drive. The Kingdom encourages women to practice several sports without compromising Islamic teaching or social norms. In 2013, the concerned authorities in Saudi Arabia decreed women are allowed to ride bicycles in recreational areas on condition they dress modestly and are accompanied by a male guardian at all times, 
(BBC, 2018). This new era of more social liberties to women should encourages designers and sportswear manufacturers to look for ways to design cycling and sportswear attires that enhance women participation in sports without compromising the Islamic teachings; Saudi social norms and governments' laws.

In light of this, the researcher has investigated the trends of women cycling activities in Saudi Arabia in addition to her preferences when it comes to cycling clothes. Knowing the preferences of Saudi women of cycling clothes would help designers and sportswear manufacturers come up with new innovative designs that fit the nature of Saudi social norms and observe the traditions and values of Saudi families. A questionnaire was designed to identify Saudi woman's preferences for cycling clothes, and investigates the current situation of women's practice of cycling in the Kingdom, with the aim to produce some recommendations that would enable sportswear designers to produce women's cycling clothes that conform to and respect social and religious values.

\section{Questionnaire Results}

Figure 1: How often do women practice cycling?

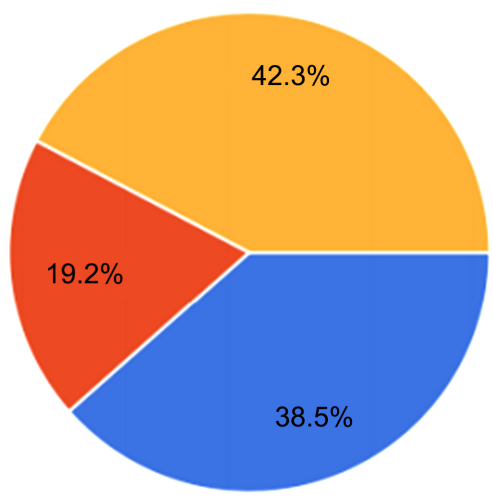

Figure 1. 38.5\% always ride bicycles; $42.3 \%$ ride bicycles occasionally and $19.2 \%$ do not ride bicycles at all.

Figure 2: What are the preferred cites for cycling?

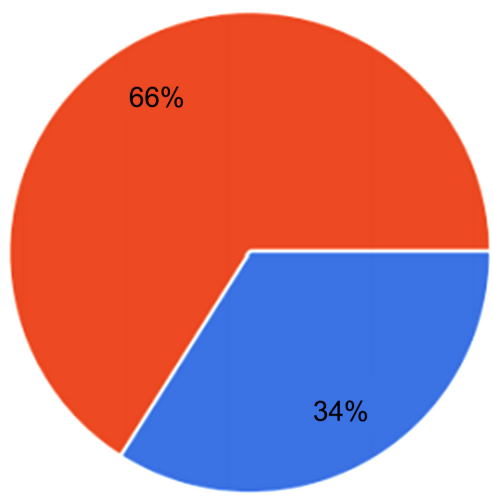

Figure $2.66 \%$ of women cycled inside private properties, while $34 \%$ cycled in public places. 
Figure 3: Do you possess specialized cycling clothes?

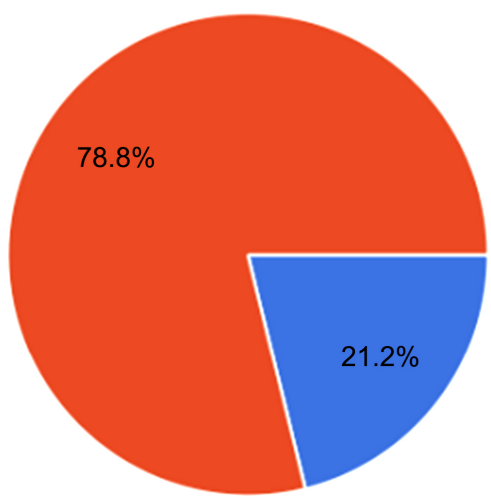

Figure 3. 78.8\% said they do not have a specialized cycling clothes; while 21.2 said they do have.

Figure 4: Are women cycling clothes available at the local market?

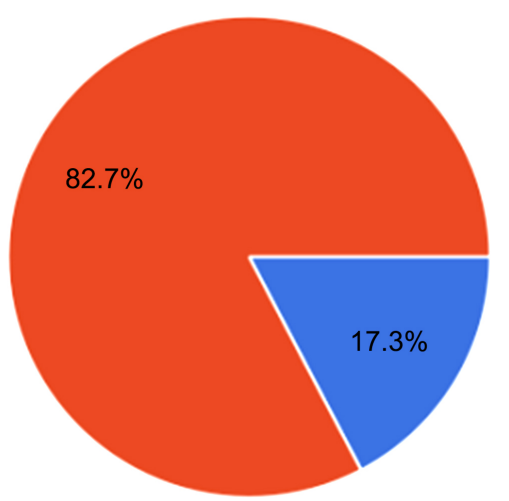

Figure $4.82 .7 \%$ of respondents said there are no stores that offer women cycling clothes in the local market and $17.3 \%$ said there are a few stores.

Figure 5: Where do women prefer to wear specialized cycling clothes?

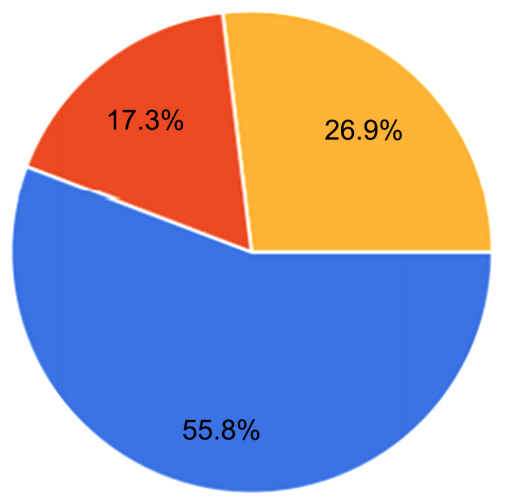

Figure 5. 55.8\% said they prefer to wear women's modest and specialized cycling clothes in the public places, $26.9 \%$ said sometimes; and $17.30 \%$ they don't prefer to do so. 
Figure 6: Are you comfortable with wearing women's modest and specialized cycling clothes?

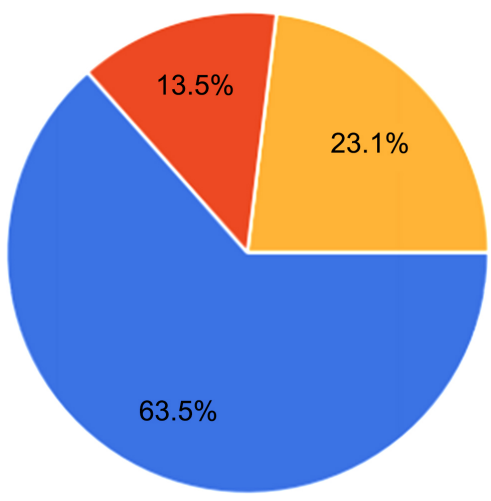

Figure 6. 63.5\% said they feel comfortable wearing women's modest and specialized cycling clothes in public places; $13.5 \%$ said they don't feel comfortable, and $23.1 \%$ said sometimes.

Figure 7: Do you prefer to wear modest and specialized cycling clothes?

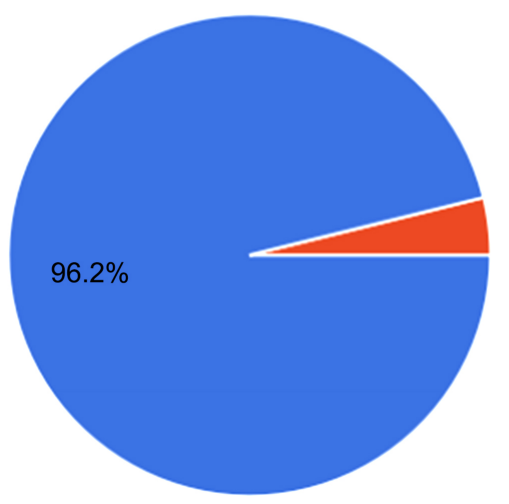

Figure 7. $96.2 \%$ said they are always very keen to wear cycling clothes that respect Islamic teachings and traditional customs.

Figure 8: Would you accept to wearing Abya-like sportswear for cycling?

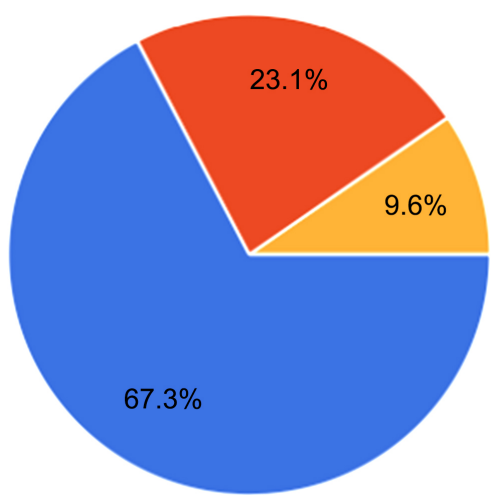

Figure 8. 67.3 of respondents said they like to wear Abya-like wear for cycling, $23.1 \%$ said they don't like so and 9.6 said they sometime prefer to wear Abaya-like sportwear. 
Figure 9: Do you prefer to wear fashionable cycling clothes?

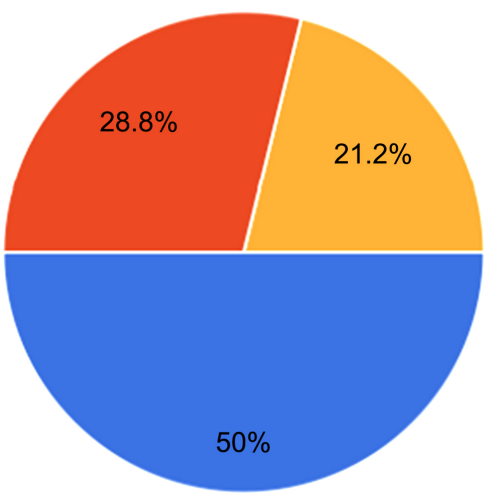

Figure 9. 50\%; said they prefer fashionable cycling clothes; $28.8 \%$ said they don't, and $21.2 \%$ said sometime.

Figure 10: Do you possess more than one design of cycling clothes?

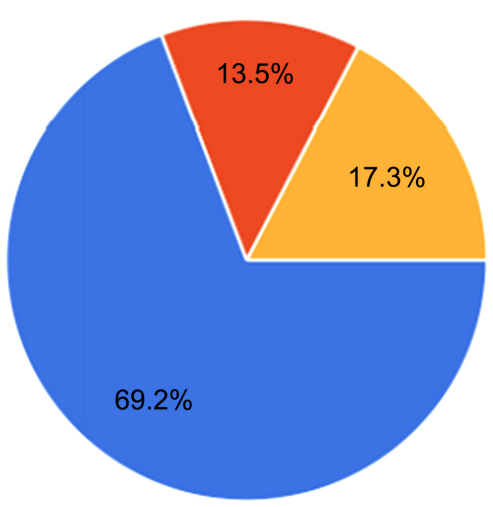

Figure 10. 69.2\% prefer to have more than one design of cycling clothes for public places; 13.5 don't prefer; 17.3 sometime they prefer so.

Figure 11: Do you preferto wear dark-colored cycling clothes?

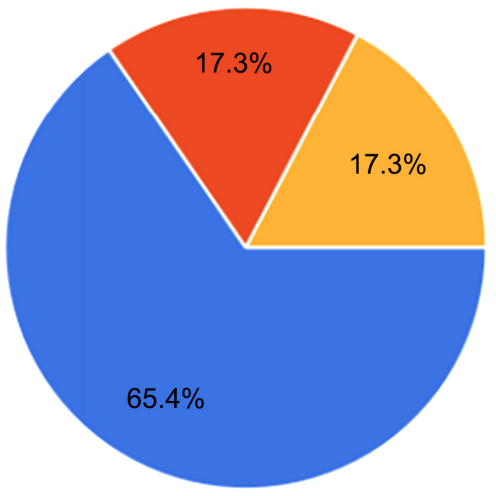

Figure 11. 65.4\% of respondents said they prefer a dark-colored cycling clothes, $17.3 \%$ said they don't, and $17.3 \%$ said they sometime they prefer to do so. 


\section{Discussion of Results and Conclusion}

The overall results of the questionnaire show a tendency among woman cyclists to wear a specialized cycling clothes that conform to traditional and cultural values.

As per the questionnaire, $38.5 \%$ of women said they do practice cycling regularly, $42.3 \%$ occasionally, and $10.2 \%$ do not cycle at all. This answers the first question concerning the practice of cycling among Saudi women, and shows that there is a growing interest in cycling among Saudi women. The result also is in line with Bonham's study, which emphasizes that women prefer cycling due to its importance to health and fitness.

The percentage of women who said they feel comfortable when wearing specialized and modest cycling clothes in public places was $63.5 \%$, signifying the need to design specialized and modest sportswear for women that conforms to traditional values and Islam teachings. This also answers the second question regarding Saudi women's preferences of modest and specialized cycling clothes.

As for the availability of stores in Saudi Arabia that sell women cycling clothes which meet the requirements of Arab societal traditions and ethics, $82.7 \%$ of respondents said there are no stores that offer such type of clothes, thus indicating that fashion designers have to produce such types of sportswear in order to fulfill Saudi women's demand for modest cycling clothes. This is also further enhanced by the fact that $96.2 \%$ of respondents said they are always very keen to wear cycling clothes that respect Islamic teachings and traditional values. Again, 67.3 of respondents said they like to wear Abya-like wear for cycling, $23.1 \%$ said they don't like so and 9.6 said they sometime prefer to do so, and $65.4 \%$ of respondents said they prefer a dark-colored cycling clothes, $17.3 \%$ don't, and $17.3 \%$ said they sometime they prefer to do so. These results are clear indication that women have tendencies to buy modest cycling clothes that enable them to practice cycling comfortably without compromising their customs and modest appearance.

\section{Recommendations}

Two recommendations have been produced in this research as follows:

The need to organize workshops that would raise women's awareness on the importance of cycling.

The need to urge fashion designers and merchants to take into consideration the production of various types of women's sportswear that observe Islam's teachings as well as the social norms of Saudi families.

\section{Conflicts of Interest}

The authors declare no conflicts of interest regarding the publication of this paper.

\section{References}

Arab News (2020). First Saudi Cycling Championship Crowns Four Female Winners, 
2020. https://www.arabnews.jp/en/saudi-arabia/article 24996/

BBC (2018). Saudi Arabia Hosts Its First Ever Women's Cycle Race. https://www.bbc.com/news/blogs-trending-43740203\#: :text=In\%202013\%20the\%20a uthorities\%20in,male $\% 20$ guardian\%20at\%20all\%20times

Blickenstaff, B. (23 September 2016). Annie Londonderry: The Self-Promoting Feminist Who Biked around the World. Vice.

Brown, Herbert E. (1895). Betsey Jane on Wheels: A Tale of the Bicycle Craze. W. B. Conkey.

Christie-Robin, J. et al. (2012) From Bustles to Bloomers: Exploring the Bicycle's Influence on American Women's Fashion, 1880-1914. The Journal of American Culture, 35, 315-331. https://doi.org/10.1111/jacc. 12002

Encyclopædia Britannica (2020). Cycling-Sport. Encyclopædia Britannica.

Encyclopedia of Islam and the Muslim World (2003). p. 721. New York: Macmillan Reference USA.

Flanders, J. (2007). Consuming Passions: Leisure and Pleasure in Victorian Britain. London, New York, Toronto and Sydney: Harper Perennial.

Hallenbeck, S. (2010). Riding Out of Bounds: Women Bicyclists' Embodied Medical Authority. Rhetoric Review, 29, 327-345. https://doi.org/10.1080/07350198.2010.510054

Harmond, R. (1971). Progress and Flight: An Interpretation of the American Cycle Craze of the 1890s. Journal of Social History, 5, 235-257. https://doi.org/10.1353/jsh/5.2.235

Jazouli, A. (2019). The Importance of Cycling Exercise on Elderly Asthma Patients (60 50 Years). Master Research, Abdul Hamid Bin Badis Mostaganem University.

Kiersnowska, B. (2019) Female Cycling and the Discourse of Moral Panic in Late Victorian Britain. Atlantis, 41, 85-103.

Mackintosh, P. G., \& Norcliffe, G. (2007). Men, Women and the Bicycle: Gender and Social Geography of Cycling in the Late-Nineteenth Century. In Horton, Rosen and Cox 2007 (pp. 153-178).

Martin, R. C. et al. (2003). Encyclopedia of Islam \& the Muslim World. New York: Macmillan Reference.

Oxford English Dictionary (1989). Cycling: The Action or Activity of Riding a Bicycle etc. (2nd ed.) Oxford: Oxford University Press.

Pfister, G. (2010). Women and Sport in Islamic Countries. Forum for Idræt, 26, 35-49. https://doi.org/10.7146/ffi.v1i1.31586

Reid, C. (2015). Roads Were Not Built for Cars. Washington DC: Island. Rubenstein. https://doi.org/10.5822/978-1-61091-688-2

Rubinstein, D. (1977). Cycling in the 1890s. Victorian Studies, 21, 47-71.

Saudigazette (2020). SFA-Held Women's Cycling Race Series Proves a Success. https://saudigazette.com.sa/article/586509

Stanton, E. C. (1902). Elizabeth Cady Stanton Papers: Speeches and Writings-1902 Articles; Undated; Shall Women Ride the Bicycle? Undated. Library of Congress, Library of Congress.

Willard, F. E. (1895). A Wheel within a Wheel: How I Learned to Ride the Bicycle with Some Reflection by the Way. Fleming H. Revell Company. 